\title{
Artikel
}

\section{Met recht een zorg}

\author{
Lokale sociale professionals als poortwachters van de Wet maatschappelijke ondersteuning \\ 2015
}

D. Claessen MSc, mr. dr. Q.A.M. Eijkman en dr. M. Lamkaddem*

\section{Inleiding}

Op basis van een casestudy gaat dit artikel in op de mate van juridische kennis van lokale sociale professionals in een wijkteam in Amersfoort over de Wet maatschappelijke ondersteuning 2015 (Wmo 2015). Daarnaast worden knelpunten besproken die zij ervaren in de uitvoering van de juridische procedure. Onder mandaat van de gemeente bereiden zij een besluit voor over een maatwerkvoorziening terwijl zij hier niet per se voor zijn opgeleid. Onbekend is of zij zich bewust zijn van de juridische aspecten. Vanaf oktober 2016 tot februari 2017 zijn drie keukentafelgesprekken geobserveerd tussen sociale professionals van dit wijkteam met mensen met een beperking. Daarnaast is één casusoverleg geobserveerd en zijn zes professionals geinterviewd. Vier keukentafelgesprekken zijn geobserveerd met mensen met een cognitieve beperking en hun belangenbehartigers in andere Utrechtse gemeenten. ${ }^{1}$ De resultaten worden besproken in dit artikel nadat we het besluitvormingsproces op papier beschrijven. In de laatste para-

* D. (Dorien) Claessens is docent/onderzoeker bij het lectoraat Toegang tot het Recht van de Hogeschool Utrecht. Mr. dr. Q.A.M. (Quirine) Eijkman is lector Toegang tot het Recht en Ondervoorzitter van het College voor de Rechten van de Mens (haar bijdrage is op persoonlijke titel geschreven). Dr. M. (Majda) Lamkaddem is docent/senior onderzoeker bij het lectoraat Toegang tot het Recht van de Hogeschool Utrecht.

1. Claessen, D., Eijkman Q.A.M., Lamkaddem, M. (2017). Hulp en recht aan de keukentafel: De toegang tot de Wet maatschappelijke ondersteuning volgens lokale professionals. Utrecht: Kenniscentrum Sociale Innovatie, Hogeschool Utrecht. graaf worden onbedoelde consequenties van de rol van het wijkteam in kaart gebracht. Ook worden er anbevelingen gedaan om de kwaliteit van besluitvorming te verbeteren zodat de rechtspositie van mensen met een beperking sterker gewaarborgd kan worden.

\section{Van recht op zorg naar maatwerk}

Sinds de decentralisaties van 2015 houden gemeenten zich meer dan ooit bezig met de zorg, ondersteuning en participatie van burgers. Er is een fundament gelegd voor Verzorgingssteden waarin niet zozeer protocollen leidend zijn, maar waar burgers en professionals samen uitvinden hoe iemand met een beperking vanuit de eigen leefomgeving kan participeren in de samenleving. Standaard diensten zoals aangeboden onder het oude stelsel van de Algemene Wet Bijzondere Ziektekosten (AWBZ) zijn per 1 januari 2015 vervangen door persoonlijk maatwerk: een op de persoon toegesneden oplossing voor een participatie- en/of zelfredzaamheidsprobleem. Waar mensen met een beperking voorheen recht hadden op zorg als zij aan bepaalde voorwaarden voldeden, is er krachtens de Wmo 2015 sprake van een voorziening als blijkt dat iemand het niet op eigen kracht redt. Daarmee lijkt de wetgever overgestapt van gelijkheid als dragend rechtsidee bij de toegang tot zorg naar ieder het zijne. 
In zo'n 90 procent $^{2}$ van de gemeenten zijn wijkteams opgericht met sociale professionals die zich verdiepen in de persoonlijke situatie van mensen die zich melden met een ondersteuningsvraag. Hieruit moet blijken of iemand zijn beperkingen het hoofd kan bieden met algemeen toegankelijke voorzieningen zoals hulpverlening door het wijkteam en de inzet van het eigen netwerk. Als dit niet afdoende is, dan kan de cliënt een aanvraag doen voor een maatwerkvoorziening zoals huishoudelijke zorg, een woningaanpassing of specialistische begeleiding. Vaak heeft een wijkteam in de praktijk het gemeentelijke mandaat om een besluit over een maatwerkvoorziening voor te bereiden en te nemen. Deze lokale sociale professionals hebben daarmee een dubbele taak: als hulpverlener dienen ze de belangen van hun clienten te behartigen en als poortwachter moeten ze bepalen wie in aanmerking komt voor voorzieningen op basis van de Wmo 2015. Gesprekken aan de keukentafel met cliënten eindigen dus niet per se in een besluit. Het is voor burgers en hun mantelzorgers daarom niet altijd duidelijk wie formeel beslist: de gemeente of het wijkteam. ${ }^{3}$

Door deze professionals te laten communiceren met burgers, wordt gestreefd naar een gehumaniseerde rechtsbetrekking. Ondersteuningsvragen zouden dan op een informele, minder juridische en laagdrempelige manier afgehandeld kunnen worden. Door de toenemende nadruk op maatwerk hebben zij meer ruimte voor professionele oordeelsvorming gebaseerd op ervaring en reflectie waarbij moraliteit, persoonlijke idealen en normatieve overwegingen inherent verbonden zijn met hun handelen. ${ }^{4}$ Burgers kunnen dan tegelijkertijd op hun eigen verantwoordelijkheid gewezen worden op een manier die vrijwel niet leidt tot juridische geschillen: door in samenspraak na te gaan welke voorzieningen passend zijn, kunnen deze immers in een informeel hulpverleningstraject worden opgelost - zonder juridische middelen als een bezwaarschrift of beroep. ${ }^{5}$

Voor mensen die afhankelijk zijn van voorzieningen op basis van de Wmo 2015 is de manier waarop professionals in een wijkteam wet- en regelgeving begrijpen en implementeren uiterst belangrijk. Vooralsnog is niet bekend of deze lokale professionals zich bewust zijn van de juridische aspecten van hun besluitvorming. Daarom gaan we eerst in op besluitvorming op papier en vervolgens besluitvorming in de praktijk van het keukentafelgesprek.

2. Van de G32-gemeenten werkt $96 \%$ met sociale (wijk)teams. Bij de overige (middelgrote tot kleine) gemeenten is dat $86 \%$. Zie verder: Arum, S., \& Schoorl, R. (2015). Sociale (buurt)teams in beeld: Stand van zaken na de decentralisaties. Utrecht: Movisie.

3. Eijkman, Q.A.M. (2017). Toegang tot het recht gaat glocal (Openbare les). Utrecht: Kenniscentrum Sociale Innovatie, Hogeschool Utrecht.

4. Jacobs, G., Meij, R., Terwolde, H. \& Zomer Y. (red.). (2008). Goed werk. Verkenningen van normatieve professionalisering. Amsterdam: Humanistics University Press.; Van Doorn, L. (2008). Sociale professionals en morele oordeelsvorming (Openbare les). Utrecht: Kenniscentrum Sociale Innovatie, Hogeschool Utrecht.

5. Vonk, G., Klingenberg, A., Munneke, S., \& Tollenaar, A. (2016). Rechtstatelijke aspecten van de decentralisaties in het sociale domein. Groningen: Rijksuniversiteit Groningen.

\section{Besluitvorming op papier}

Op basis van de Wmo 2015 biedt de gemeente maatschappelijke ondersteuning en levert zo nodig hulp bij algemene dagelijkse levensverrichtingen en een gestructureerd huishouden zodat iemand zo lang mogelijk vanuit de eigen leefomgeving kan participeren. ${ }^{6}$ Iemand kan zich melden met een participatie- of zelfredzaamheidsprobleem, maar ook met een concrete vraag zoals een aanvraag voor huishoudelijke zorg. Vanuit de Algemene wet bestuursrecht (Awb) bekeken, is het van belang of de vraag van de burger een aanvraag is, ofwel een verzoek aan het bestuursorgaan om een besluit te nemen. Krachtens de Wmo 2015 kan echter elk verzoek worden gezien als een vraag voor ondersteuning bij het vergroten van de zelfredzaamheid of participatie. Dit resulteert in een besluitvormingsproces met maximaal vijf stappen: melding, verslag, aanvraag, besluit en uitvoering.

Gemeenten zijn na de melding wettelijk verplicht onderzoek te doen naar de persoonlijke situatie van deze burgers. ${ }^{7}$ Vaak zijn wijkteams gemandateerd om dit proces, al dan niet gedeeltelijk, uit te voeren. ${ }^{8}$ De sociale professionals hebben dan de inspanningsverplichting om mantelzorger(s) van de cliënt bij het gesprek te betrekken. Ook dient het wijkteam mensen erop te wijzen dat ze zich kunnen laten bijstaan door een onafhankelijke clientondersteuner en de mogelijkheid tot het indienen van een persoonlijk plan dat meegenomen dient te worden bij het onderzoek. ${ }^{9}$ De professional brengt vervolgens in kaart hoe zelfredzaamheid en participatie kunnen worden verbeterd door in samenspraak met de cliënt en de mantelzorgers te komen tot een onderbouwd plan.

Dit leidt tot een verslag waarin de professional vastlegt wat er afgesproken is of voorgesteld wordt als oplossing voor de problemen. Daarbij kunnen diverse maatwerkoplossingen voorgesteld worden: verder gaan op eigen kracht, het inschakelen van het eigen netwerk, gebruikmaken van een algemene voorziening of een maatwerkvoorziening. Als dat laatste het geval is dan moet de client een aanvraag ${ }^{10}$ indienen door het verslag te ondertekenen, binnen zes weken na de melding. Vervolgens neemt het wijkteam, namens de gemeente, binnen twee weken een besluit over een maatwerkvoorziening. In de andere drie gevallen is met het verzenden van het verslag de procedure in reactie op de melding afgerond. Als de conclusie van het verslag is dat de cliënt geen aanspraak maakt op een maatwerkvoorziening dan kan hij alleen door toch een aanvraag in te dienen een besluit in

9

10. Een aanvraag hoeft niet altijd een afzonderlijk schrijven aan B\&W te zijn. In de praktijk wordt wel een werkwijze gehanteerd dat, als uit het keukentafelgesprek duidelijk wordt dat het wijkteam namens de gemeente vindt dat recht bestaat op een maatwerkvoorziening en de betrokkene die ook wil hebben, dit in het verslag wordt aangetekend en van de handtekening van de cliënt wordt voorzien. Het verslag fungeert vervolgens als aanvraag. 


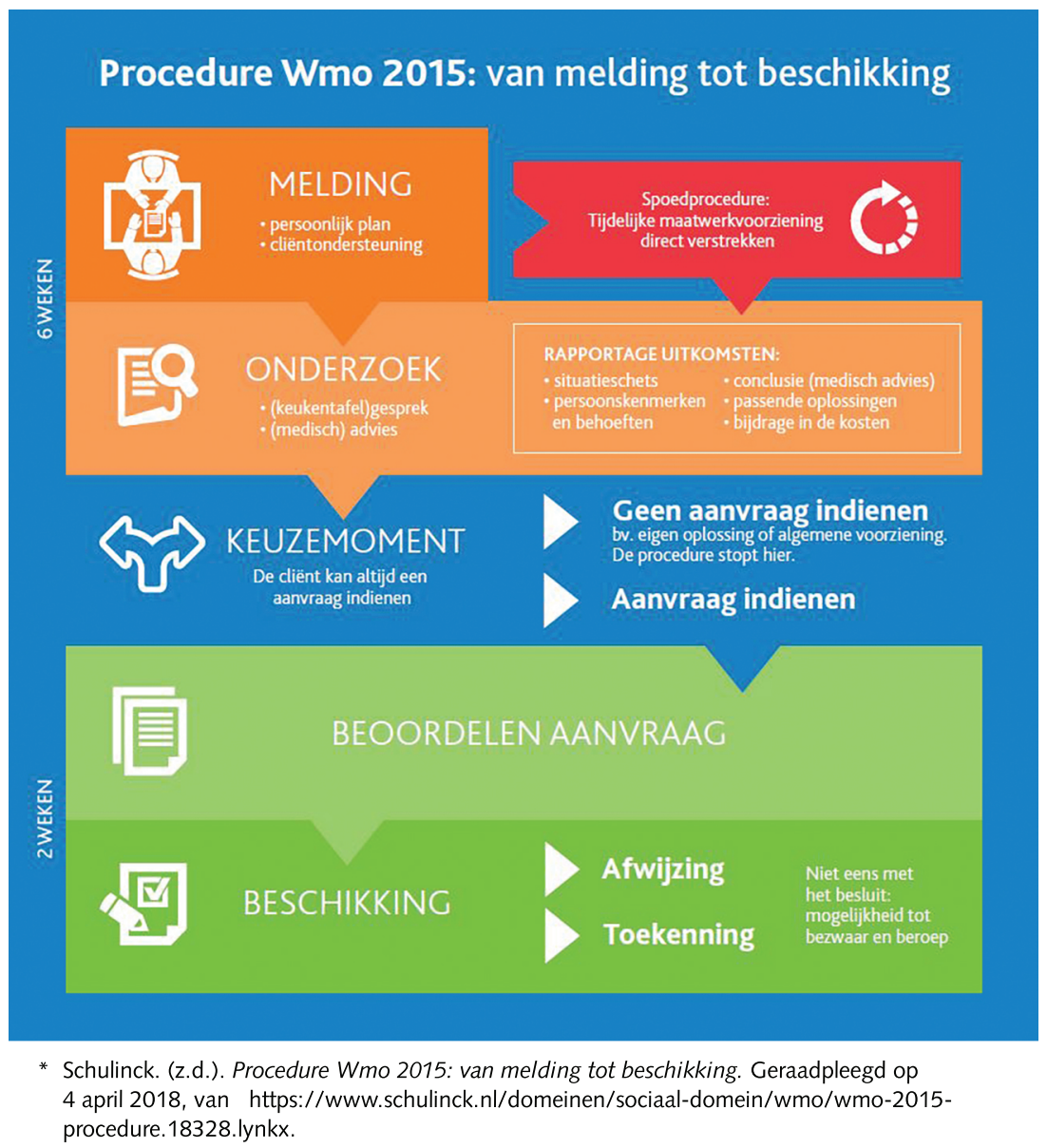

handen te krijgen waartegen bezwaar en beroep mogelijk is. $^{11}$

\section{Besluitvorming rond de keukentafel}

De werkwijze van wijkteams verschilt in meer of mindere mate per gemeente. Er zijn echter beleidsmatige uitgangspunten, zoals met generieke kennis gebiedsgericht anticiperen op vragen van burgers. ${ }^{12}$ Ondersteuningsvragen van cliënten worden integraal aangepakt wat bij het wijkteam in deze casestudy gevat wordt in zeven kernfuncties: $:^{13}$ 1) beslissen over de toegang tot gemeentelijk gefinancierde voorzieningen; ${ }^{14}$ 2) wegwijzen naar de basisinfrastructuur, ${ }^{15} 3$ ) voeren van regie in het kader van één huishouden, één plan, één regisseur; 4) vraag

11. Marseille, A.T. \& Vermaat, M.F. (2017). 'Burgers op zoek naar rechtsbescherming in het sociaal domein.' Handicap \& Recht, 2 (1), p. 9-15.

12. De Waal, V. (2016). Sociale (wijk)teams onderzocht: zicht op ontwikkelingen en knelpunten. Utrecht: Kenniscentrum Sociale Innovatie, Hogeschool Utrecht.

13. Rekenkamer Amersfoort. (2017). Rekenkameronderzoek. Effectiviteit en efficiëntie sociale wijkteams Amersfoort. Geraadpleegd op 5 april 2018, van https://www.nvrr.nl/bibliotheek/79446/Effectiviteit-enefficiëntie-sociale-wijkteams-Amersfoort.

14. Met uitzondering voor inkomensvoorzieningen en arbeidstoeleiding.

15. Onder de basisinfrastructuur vallen voorzieningen in de wijk en de gemeente, zoals de woningbouw, buurthuizen of vrijwilligersorganisaties. verhelderen; 5) versterken eigen kracht; 6) uitvoeren van ambulante zorg en ondersteuning op het gebied van Jeugdzorg, Wmo 2015 en sociale zekerheid; 7) signaleren. ${ }^{16}$ Tijdens keukentafelgesprekken van het wijkteam in deze casestudy wordt de zelfredzaamheid van een client in kaart gebracht met de Zelfredzaamheid-Matrix (ZRM).${ }^{17}$ De sociale professional inventariseert de mate van zelfredzaamheid op leefgebieden zoals inkomen, tijdsbesteding, geestelijke gezondheid, lichamelijke gezondheid, algemene dagelijkse levensverrichtingen, sociaal netwerk, maatschappelijke participatie en middelengebruik.

\subsection{Juridische kennis van lokale sociale professionals}

In dit onderzoek hebben we gekeken naar de kennis van lokale sociale professionals over de procedure van de Wmo 2015. Zij lijken die kennis in enige mate te hebben. De mogelijkheid voor cliënten om een persoonlijk plan in te dienen kwam niet ter sprake tijdens de interviews, noch tijdens de in totaal zeven geobserveerde keukentafelgesprekken. De professionals zijn op de hoogte van onafhankelijke cliëntondersteuning, maar lij-

16. Signaleren wordt in deze gemeente omschreven als: breed te kijken naar een hulpvraag door eventuele andere knelpunten in het functioneren te bevragen.

17. Het is onbekend hoeveel gemeenten en wijkteams met deze matrix werken. Zie verder: Movisie. (2017, 17 september). De Zelfredzaamheid-Matrix (ZRM). Geraadpleegd op 5 april 2018, van https://www. movisie.nl/tools/zelfredzaamheid-matrix-zrm. 
ken zich nauwelijks bewust dat cliënten daarvan op de hoogte gesteld zouden moeten worden tijdens de melding. ${ }^{18}$ Alle professionals zijn op de hoogte van de mogelijkheid voor cliënten om bezwaar te maken bij de gemeente tegen het besluit van het wijkteam. Als op basis van het keukentafelgesprek besloten wordt dat de cliënt recht heeft op een maatwerkvoorziening en de client wil die ook hebben, dan dient de rapportage met de uitkomsten door de cliënt ondertekend te worden. Deze rapportage fungeert vervolgens als aanvraag. Professionals vertelden echter dat cliënten de rapportage kunnen ondertekenen 'voor akkoord' of 'voor gezien'. Door voor akkoord te tekenen doen ze een aanvraag voor een maatwerkvoorziening als het wijkteam vond dat het recht daarop bestond. Door voor gezien te ondertekenen werd slechts bevestigd dat het verslag ontvangen was. In dat geval doet de cliënt geen aanvraag waardoor hij geen besluit in handen krijgt waartegen bezwaar mogelijk is. Op de vraag of cliënten dit onderscheid begrijpen, antwoordt een van de geïnterviewden dat het team dit niet goed begrijpt, en dat cliënten het 'dan al helemaal niet begrijpen'.

De professionals zijn op de hoogte van de wettelijke termijnen die zijn vast gelegd in werkprocessen en een ICT-systeem. Zij krijgen een melding in het systeem als de termijn niet behaald is. De statistieken die daaruit voortvloeien worden door de gemeente teruggekoppeld aan de teamleider die dit bespreekt met de professionals.

\subsection{Hulp en recht in de praktijk}

6 Op weg naar een keukentafelgesprek, eind november 2016, vertelt een professional: 'Het gaat erom om op basis van kennis, ervaring en intuitie te komen tot maatwerk en dat dan ook nog eens juridisch passend te maken.' Het keukentafelgesprek dat zij voert verloopt daarna als volgt:

De professional legt een bejaarde dame en haar thuiswonende zoon uit dat het doel is om te kijken of de beschikking voor dagbesteding verlengd moet worden. De vrouw zegt dat ze dit ontzettend hoopt, want na een periode waarin ze niet meer wilde leven kwam de dagbesteding als een 'geschenk'. Ze beantwoordt de vragen van de professional niet eenduidig, maar vertelt allerlei gebeurtenissen uit haar leven. De professional luistert geinteresseerd en stelt regelmatig een vraag in dienst van haar onderzoek. Na drie kwartier geeft ze aan dat het haar duidelijk is geworden dat mevrouw heel graag naar de dagbesteding blijft gaan. Ze legt uit dat zij deze beslissing niet alleen neemt, maar met collega's. Ze belooft de dame meteen na de vergadering, twee dagen later, te bellen.

$\mathrm{Na}$ het gesprek zegt de professional dat ze het vervelend vindt om de dame in onzekerheid achter te laten, omdat zij zich waarschijnlijk zorgen zal maken terwijl het duidelijk is dat de beschikking moet worden verlengd.

18. Vaak zijn zij hier niet direct bij betrokken omdat de melding binnenkomt via een centraal telefoonnummer waarna mensen naar het juiste wijkteam in de stad worden verwezen.
Toch staat ze achter haar handelen: ze vindt het belangrijk dat het besluit met het team genomen wordt. Ook haar collega's blijken te hechten aan het gezamenlijk dragen van de verantwoordelijkheid voor een besluit. Hun wekelijkse teamoverleg heeft de bedoeling om kennis en ervaring te delen en zou de totstandkoming van eenzelfde beoordelingskader bevorderen. Om dezelfde reden voeren professionals het keukentafelgesprek vaak in tweetallen. De professionals zijn zich bewust van subjectiviteit van hun besluitvorming. Dit blijkt uit de volgende passage uit het groepsinterview:

Professional 1: Soms word je teruggestuurd met 'doe nog maar wat extra onderzoek'. En soms denk je: 'nu moet ik flink aan de bak om dit voor elkaar te krijgen en heb je binnen vijf minuten een beschikking'.

Professional 2: Het is een verrassing, elke keer weer. [Lach]

Professional 1: Ja, en het kwetsbare vind ik wel dat het afhangt van hoe goed wij het woorden geven.

Professional 2: En wie het doet of een cliënt krijgt wat hij nodig heeft.

Professional 1: Of wat de cliënt wil.

Professional 3: Ja, het houd je wel scherp ja.

Professional 1: Ja, dus dat vind ik wel best pittig.

(groepsinterviem sociale professionals, februari 2017)

In de teamvergadering van dit wijkteam wordt de rapportage in een format geprojecteerd op de muur, waarbij de professional die het keukentafelgesprek voerde dit toelicht. Vervolgens bevragen de overige teamleden het onderzoek aan de hand van de zogeheten zeven 'leidende principes' die in samenwerking met de gemeente zijn ontwikkeld. Deze zijn: 1) veiligheid van het kind/de burger staat voorop; 2) één gezin, één plan, zo veel mogelijk één gezicht; 3 ) versterken eigen kracht (door de generalistische professional als coach): 4) vroeginterventie en preventie voorop; 5) cliëntvraag is leidend bij het inrichten van de zorg (niet het aanbod van een zorgaanbieder); 6) zo effectief mogelijk doorverwijzen (als aanvullende zorg nodig is); 7) betrekken en benutten van sociale basisvoorzieningen. ${ }^{19}$ In de overlegruimte liggen deze principes geplastificeerd op tafel. Uit meerdere interviews blijkt dat de leidende principes onvoldoende houvast geven bij het nemen van een besluit over een maatwerkvoorziening en daarom zoeken ze naar criteria, zoals duidelijk wordt in het volgende voorbeeld uit een individueel interview:

Professional: (...) die mensen vragen een PGB voor eigenlijk 28 uur verzorging en begeleiding per week voor een familielid. (...) Wij komen echt niet hoger uit dan 20,5 uur op basis van wat zij aanleveren.

Onderzoeker: Hoe kom je aan een totaalaantal uren?

Professional: De cliënten hebben uitgeschreven wat ze doen. Wij zijn gaan kijken wat zou je redelijkerwijs

19. Rekenkamer Amersfoort. (2017). Rekenkameronderzoek. Effectiviteit en efficiëntie sociale wijkteams Amersfoort. Geraadpleegd op 5 april 2018, van https://www.nvrr.nl/bibliotheek/79446/Effectiviteit-enefficiëntie-sociale-wijkteams-Amersfoort. 
kunnen beschikken en wat valt onder gebruikelijke zorg. (...) Net als bij de thuiszorg staat daar een aantal minuten voor. Dan reken je dat.

Onderzoeker: Zijn er standaarden om die tijd in te delen, te berekenen?

Professional: Nee, en dat is het vervelende. Vanuit persoonlijke verzorging weet een collega [verpleegkundige] dat, omdat ze voor de thuiszorg werkte. Die uren houd je dan maar gewoon aan. Ja, waarom zouden we ervan afwijken, die tijden zijn er niet voor niets. Met uren [persoonlijke] begeleiding heb je [echter] geen enkel houvast.

(individueel interviem professional, december 2016)

De professional houdt er in deze casus rekening mee dat de mantelzorgers namens de cliënt bezwaar aantekenen tegen het besluit van het wijkteam. Een bezwaarschrift, gevolgd door een eventuele beroepszaak, ziet zij in dit geval als meerwaarde: 'Soms is het ook maar fijn om het voor een rechter te krijgen, want dan ontstaat er jurisprudentie en weten we wat blijft staan en wat niet. Want op die manier leer je ook. $\mathrm{Nu}$ is er geen jurisprudentie over, dus je bent ook nog helemaal vrij. Wat kan wel en wat kan niet?'

Professionals lijken een bezwaarprocedure echter vooral te vermijden, zo blijkt onder andere uit de volgende passage uit het groepsinterview:

Professional 1: Ik heb nu een zaak waar veel gedoe is. Je wilt voorkomen zeg maar dat er een bezwaar wordt ingediend want dan is er nog meer werk en daarom duurt het soms langer dan zes weken om overeenstemming te krijgen met elkaar om een klap erop te geven.

Professional 2: Het is voor niemand helpend.

Professional 1: Het is voor niemand helpend en zeker niet voor de cliënt.

Professional 3: Dus dan doe je wat eerder water bij de wijn?

Professional 2: Nee, dat niet!

Professional 1: Nee, nee dat niet nee. Nee, je gaat meer de gesprekken aan en je wilt weten waarom ze dingen doen zoals ze doen zeg maar en waarom ze denken dat ze er recht op hebben.

In een individueel interview geeft een professional aan dat een cliënt niet terecht kan bij het wijkteam voor ondersteuning bij een eventueel bezwaar tegen het besluit. Zij geven de voorkeur om opnieuw in gesprek te gaan. Onafhankelijke cliëntondersteuners, die zouden moeten toezien op de rechtsbescherming van cliënten tijdens de procedure, komen we niet tegen bij de zeven geobserveerde keukentafelgesprekken. Het recht op onafhankelijke cliëntondersteuning komt bij de gesprekken met professionals alleen ter sprake als we er rechtstreeks naar vragen zoals tijdens het groepsinterview:

'Het kan ook voor ons heel ondersteunend zijn dat ze erbij zijn. Ze geven aanvullende informatie, MEE [organisatie die o.a. onafhankelijke cliëntondersteu- ning biedt] weet soms dingen die wij niet weten, dat kan handig zijn. En het kan de cliënt ook geruststellen dat er iemand met hen meekijkt waardoor het hele proces soepeler verloopt. Het kan ook weleens tegenwerken, dat er iemand naast zit waarvan je denkt: nou, hier worden we niet zo gelukkig van omdat die zelf al de hakken in het zand zet. Dus dat wisselt.'

Deze professional wist dat onafhankelijke cliëntondersteuning een 'recht is'. Daarnaast lijken professionals het belangrijk te vinden dat mensen informatie krijgen over de procedure. Zo begint iedere professional het keukentafelgesprek met een korte uitleg over de werkwijze van het wijkteam afgestemd op hun inschatting van het vermogen van de cliënt. Als te veel informatie naar hun mening leidt tot een afbreuk vertrouwen, bijvoorbeeld als een dementerende cliënt daarvan in de war raakt, dan beperken ze de uitleg.

Op de vraag hoe zij juridische kennis vergaren, antwoordt een professional: 'Je besmet elkaar met informatie'. Later vertelt ze: 'We laten ons [in het dagelijkse werk] niet zo bepalen door de juridische kaders. Je komt er eigenlijk alleen mee in aanraking als de klant het niet eens is met je. Dus op het moment dat er een klacht of een bezwaar gaat komen, krijg je te maken met de juridische kaders. Dan ben je je opeens bewust van: "O ja, ik moet het dus wel allemaal op een bepaalde manier onderbouwen. Wat staat er eigenlijk in de verordening en de nadere regels van de gemeente? Wat wij zeggen, houdt dat juridisch wel stand?"”

Professionals lijken bij het formuleren van hun besluit vooral woorden in de geest van de wet te kiezen. Dat blijkt uit de volgende uitspraak van dezelfde professional: 'Het is belangrijk om in de conclusie [van de rapportage] al te spreken over zelfredzaamheid en participatie. (...) Nou ja, als je dat dan op die manier verwoordt: op basis van ons onderzoek is gebleken dat u niet zelfredzaam bent en niet zelfstandig kunt participeren vanwege die en die beperkingen. Als u die niet krijgt dan gebeurt er dit, dit en dit en daarom is het noodzakelijk om die en die redenen dat u specialistische hulp krijgt. Dan heb je het binnen de kaders van de Wmo onderbouwd waarom je iemand iets beschikt.'

\section{Met recht een zorg}

Lokale sociale professionals hebben een belangrijke rol bij het waarborgen van de rechtspositie van mensen met een beperking aan de poort van de Wmo 2015. Dit artikel gaf inzicht in de wijze waarop zij de Wmo 2015 begrijpen en uitvoeren. Op basis van één casestudy van een wijkteam in Amersfoort, die plaatsvond tussen eind 2016 tot begin 2017, suggereren wij dat deze professionals enige kennis hebben van deze wet. Juridische kaders lijken voor hen vooral van belang geworden doordat zij door een bezwaarprocedure aansprakelijk gesteld kunnen worden voor hun besluit over een maatwerkvoorziening. 
In de praktijk hebben zij te maken met meerdere juridische knelpunten. Ten eerste is er een spanningsveld omdat zij enerzijds de expliciete opdracht hebben om de eigen kracht van mensen te bevorderen. Juridische empomerment van burgers tijdens het onderzoek in het kader van de Wmo 2015 kan echter leiden tot professioneel risico omdat zij namens de gemeente het besluit over een maatwerkvoorziening voorbereiden en in de praktijk nemen. Het vergt juridische kennis en professionele moed om zich te positioneren in het belang van de burger en de eigen aansprakelijkheid te incasseren. Mede doordat ze niet per se zijn opgeleid om met deze dubbele pet om te gaan, bestaat het risico dat ze juridische aansprakelijkheid vermijden. Ten tweede opereren zij op glad ijs ten aanzien van het waarborgen van wettelijke normen. Door de toenemende nadruk op maatwerk hebben professionals handelingsruimte om op basis van ervaring en reflectie te komen tot een oordeel over een maatwerkvoorziening. Ze onderschrijven dit met woorden in de geest van de wet zonder de juridische normen werkelijk te kunnen waarborgen. Dit heeft consequenties voor de rechtspositie van de cliënt. Ten derde ligt hun hart en hoofd vaak bij het opbouwen van een vertrouwensrelatie met mensen en geven ze soms minder gewicht aan de juridische kant van de zaak, vooral als iemand daardoor in de war zou raken, door bijvoorbeeld dementie. Ze zijn daardoor in mindere mate gericht op het voorbereiden van een zorgvuldige rechtsbetrekking. Sociale wijkteams brengen de veranderende rechtsbetrekking tussen de overheid en burgers tot stand. Deze institutionele context draagt bij aan een gehumaniseerde rechtsbetrekking. Enerzijds kan hierdoor rekening worden gehouden met de persoonlijke situatie van mensen, en zijn er minder juridische procedures die tot vertraging leiden; klachten worden afgehandeld door sociale professionals in gesprek te laten gaan met burgers. Anderzijds heeft dit onbedoelde gevolgen voor de organisatie van de geschillenbeslechting. De Nationale ombudsman constateert dat burgers niet altijd een klacht indienen omdat zij bang zijn voor de gevolgen voor de verhouding tot de gemeente of het wijkteam. ${ }^{20}$ Wijkteams kunnen juridisering te veel voorkomen waardoor klachten, die uiteindelijk kunnen bijdragen aan het ontstaan van jurisprudentie, verhuld blijven. In de praktijk lijkt het decentralisatieproces zich dan deels te richten op het verminderen van juridische weerstand bij burgers. $^{21}$

Ondanks het feit dat op basis van de Algemene wet bestuursrecht rechtsbescherming voor burgers bestaat, toont de discussie over integrale geschillenbeslechting in het sociaal domein aan dat toegang tot het recht bij de

20. Nationale Ombudsman. (2017). Terug aan tafel, samen de klacht oplossen: Onderzoek naar klachtbehandeling in het sociaal domein na de decentralisaties. Geraadpleegd op 4 april 2018, van https://www. nationaleombudsman.nl/onderzoeken/2017035-onderzoek-naarklachtbehandeling-het-sociaal-domein-na-de-decentralisaties.

21. Tollenaar, A. (2016). 'Humane rechtsbetrekking in de lokale verzorgingsstaat.' In Vonk. G., A. Klingenberg, S. Munneke \& A. Tollenaar (red.), Decentralisaties in het sociale domein vragen om groot onderhoud aan stelsel van rechtsbescherming. Groningen: Universiteit Groningen, p. 27-60.
Wmo 2015 niet voor iedereen vanzelfsprekend is. ${ }^{22}$ Mede daarom vond de wetgever de rol van de onafhankelijke cliëntondersteuner essentieel. Het is onduidelijk hoe consciëntieus gemeenten en wijkteams deze verplichting nakomen. Wij merken bovendien dat lokale professionals de cliëntondersteuner niet altijd proactief uitnodigen aan de keukentafel. Dit kan verstrekkende gevolgen hebben voor de rechtsbescherming van mensen in een latere fase van de procedure want die wordt daardoor beïnloed. De frequentie waarmee gebruik wordt gemaakt van onafhankelijke cliëntondersteuners en de rol die zij spelen, zijn van belang om te onderzoeken voor de discussie over de rechtszekerheid van minder mondige mensen in het sociaal domein.

Beleidsmakers moeten waakzaam zijn voor al te enthousiaste aannames over het uitblijven van klachten van mensen met een beperking in het kader van de Wmo 2015. Het vermogen van wet- en regelgeving om hun positie te beschermen in het lokale krachtenveld is beperkt. Gemeenten kunnen wijkteams aanmoedigen te fungeren als lokale mensenrechtenactoren. ${ }^{23}$ Dit betekent ten eerste dat geinvesteerd wordt in professionalisering van juridische kennis over nieuwe wet- en regelgeving. Ten tweede hebben wijkteams autonomie nodig om zich te positioneren op basis van de uitgangspunten van de International Federation of Social Workers $(\mathrm{IFSW})^{24}$ gebaseerd op rechtvaardigheid en mensenrechten. Ten derde kan het betrekken van wijkteams bij het ontwikkelen van gemeentelijk beleid bijdragen aan rechtvaardigheid voor burgers als zij daarbij een kritische, al dan niet activistische positie, in kunnen nemen.

22. Scheltema, M. (2017). Advies-Scheltema over Integrale Geschilbeslechting Sociaal Domein: Advies van regeringscommissaris Scheltema over de mogelijkheid van een integrale geschilbeslechting in het sociaal domein, 3 oktober 2017, Den Haag: Ministerie van Binnenlandse Zaken- en Koninkrijksrelaties.

23. Oomen, B. \& Van den Berg, E. (2014). 'Human Rights Cities: Urban Actors as Pragmatic Idealistic Human Rights Users.' Human Rights and International Legal Discourse, 8 (2): 160-185.

24. Social work is a practice-based profession and an academic discipline that promotes social change and development, social cohesion, and the empowerment and liberation of people. Principles of social justice, human rights, collective responsibility and respect for diversities are central to social work. Underpinned by theories of social work, social sciences, humanities and indigenous knowledge, social work engages people and structures to address life challenges and enhance wellbeing. IFSW. (2014). Global Definition of Social Work. Geraadpleegd op 4 april 2018, van http://ifsw.org/get-involved/global-definition-ofsocial-work/ 